\title{
RELATÓRIO DA COMISSÃO DE DOCUMENTAÇÃO E ESTUDOS DA ABEn - 1972/73
}

\author{
Nylza da Rocha Dias de Medeiros*
}

\section{INTRODUC̣̃̃O}

A saúde como fator básico para o desenvolvimento de indivíduos e grupos sociais e a complexidade crescente das ciências da saúde modificaram o próprio conceito de saúde que, de ausência de enfermidade física, passou a ser definida em termos de equilíbrio ou de bem estar, englobados os aspectos, material e social.

O estado de saúde de uma coletividade pode ser medido através de certas estatísticas médico-sanitárias ou da capacidade instalada do recurso material que está à disposição da população em um determinado momento, para a prevenção de doenças, sua cura ou recuperação de incapacitades.

Mas não podemos esquecer o recurso humano, como elemento principal, pois é ele que, através de seu número e qualidade, irá possibilitar a utilização adequação dos recursos materiais disponíveis possibilitando o desenvolvimento.

Nessas circunstâncias, é de capital importância o conhecimento sobre os profisisonais de saúde.

Mas a Enfermagem ainda não possui dados exatos sobre seus profissionais, talvez devido à ausência de conscientização de sua importância por parte de todos.

Procuramos estudar, neste trabalho, algumas características da formação, aperfeiçoamento e aspéctos ligados às atividades do pessoal de Enfermagem.

\section{MATERIAL E MÉTODOS}

O trabalho foi iniciado através do envio, em 8 de fevereiro de 1973, pelo serviço de entrega postal, de carta circular onde assina-

* Coordenadora da Comissão de Documentação e Estudes da ABEn. 
lamos os objetivos da pesquisa e se solicitava a colaboração das faculdades de enfermagem, cursos técnicos e de auxiliar de enfermagem, seções estaduais da ABEn, e Secretarias de Saúde dos Territórios, dos Estados do Espírito Santo e Acre.

Acompanhando as cartas, seguiram questionários específicos para cada tipo de atividade num total de 176 , em duas vias, para facilitar o arquivamento dos mesmos pela instituição pesquisada e sua conferência quando necessária.

Objetivando aumentar as percentagens de respostas aos questionários e esclarecer dúvidas quanto ao seu preenchimento, enviamos 126 cartas e 90 telegramas e objtivemos $97,0 \%$ (32) de respostas no que se refere às faculdades, $89,4 \%$ (17) aos cursos técnicos, $94,7 \%$ (89) aos cursos de auxiliar de enfermagem, $51,1 \%$ (12) às Seções Estaduais ABEn e 40,0\% (2) às Secretarias de Saúde.

Os questionários foram tabulados manualmente, fazendo-se a distribuição em frequência e percentagem, além dos cálculos de média aritmética e desvio padrão.

A deficiência de pessoal burocrático, com o conseqüente acúmulo de trabalho das secretarias das Escolas, as dificuldades na remessa e recebimento de correspondência constituiram as principais limitacões deste estudo.

Nossos agradecimentos aos que nos responderam, e esperamos a colaboração de todos para o próximo ano, a fim de atingirmos $100,0 \%$ de respostas necessárias à obtenção de dados exatos.

\section{RESULTADOS OBTIDOS}

\section{FACULDADE DE ENFERMAGEM}

Em 1973, 33 faculdades brasileiras se destinam ao ensino da enfermagem. Em relação a elas, procuramos determinar os recursos utilizados para a manutenção, algumas características do ingresso e da matrícula, as graduações, os corpos docentes e discentes, além de certos níveis de produtividade do sistema educacional, mormente a evasão e repetência.

\section{Localização Geográfica}

A complexidade do desenvolvimento econômico, social e cultural ua região sudeste do país é um fator condicionante tanto no processo educativo, como no exercício profissional, daí a maior localização r.esta área: $14(42,4 \%)$. 
O maior desenvolvimento das capitais, de um modo geral, tem feito com que as faculdades se localizem nas metrópoles e tem dificultado o posterior deslocamento do profissional aí formado, para outros pontos do território. Apenas nos estados do Rio Grande do Norte, Minas Gerais, São Paulo, Paraná e Rio Grande do Sul encontramos faculdades sediadas fora da capital.

Estados como Acre, Piauí, Alagoas, Sergipe, Espírito Santo e Mato Grosso não possuem faculdades de enfermagem.

\section{Recursos utilizados para a manutenção}

Das 32 faculdades consideradas, 19 (ou seja 59,4\%), estão integradas à universidades, $2(6,2 \%)$ agregadas, $2(6,2 \%)$ anexas à universidade e $9(28,2 \%)$ constituem estabelecimentos isolados de ensino.

Independentemente do sistema pelo qual são regidas, predomina em sua manutenção o recurso público, quer seja federal $12(37,5 \%)$ estadual $6(18,7 \%)$ ou municipal $1(3,2 \%)$. A iniciativa privada participa em $13(40,6 \%)$.

Predominando a fonte pública de recursos $19(59,3 \%)$, torna-se mais fácil a correção de falhas na flexibilidade administrativa e econômica, ainda mais se atentarmos para o fato de que 35,8 são mantidas por recursos federais, tornando viável a elaboração e concretização de planos com origem central.

\section{Ingresso às Faculdades de Enfermagem}

Em 1973 foram oferecidas 1.405 vagas para a primeira série, pelas $27(84,3 \%)$ faculdades que responderam; destas a região $\mathrm{Su}-$ deste absorveu $715(50,8 \%)$.

A essas vagas increveram-se 3.456 candidatos, determinando a relação de 2,4 candidatos por vaga,demonstrando um aumento do interesse da população estudantil pela profissão.

O vestibular foi unificado por área em $22(68,7 \%)$ faculdades.

\section{Matriculas}

Em 1973 encontram-se matriculados 4.270 alunos nas diversas séries, não sendo observada uma distribuição equitativa entre elas. Assim na $1 .^{\text {a }}$ série encontramos o maior número, $1.405(32,9 \%)$ que pode ser justificado pelo aumento do número das vagas nas escolas, porém a irregularidade do fluxo também se prende à evasåo 
e. repetência. $\mathrm{Na} 2 .^{\mathrm{a}}$ série encontramos $1.304(30,5 \%)$, na $3 .^{\mathrm{a}}$ série, $950(22,5 \%)$ e na $4 .^{a}, 601(14,1 \%)$, dando a média de 133,4 alunos por faculdade.

Dos alunos do $4 .^{\circ}$ ano acima citados, $415(69,1 \%)$ optaram pela Enfermagem em Saúde Pública, 111 (18,5\%) pela Enfermagem Obstétrica e $75(12.4 \%)$ pela Enfermagem Médico Cirúrgica.

Dos 4.270 alunos matriculados, $2.354(55,1 \%)$ seguiam cursos sediados na região sudeste, $650(15,3 \%)$ na região sul $918(21,4 \%)$ na região nordeste, $266(6,2 \%)$ na região norte $82(1,9 \%)$ na região centro-oeste.

A não coincidência de vagas e de matrículas prende-se a dois fatores: nem todas as vagas são preenchidas ou matricula-se um número de alunos superior à capacidade discente do estabelecimento, como podemos observar no quadro abaixo:

\begin{tabular}{|c|c|c|c|c|}
\hline Séries & Vagas & Matriculados & $\%$ & Preenchimento \\
\hline 1. a série & 1.405 & 1.405 & & 100,0 \\
\hline 2. a série & 1.375 & 1.304 & & 94,8 \\
\hline 3. ${ }^{a}$ série & 1.362 & 960 & & 70,4 \\
\hline \multicolumn{5}{|l|}{ 4. ${ }^{a}$ série } \\
\hline Enf. Médico-Cirúrgica & 158 & 75 & & 47,4 \\
\hline Enf. Saúde Pública & 404 & 415 & & 102,7 \\
\hline Enf. Obstértica & 301 & 111 & & 36,8 \\
\hline TOTAL & 5.005 & 4.270 & & 85,3 \\
\hline
\end{tabular}

Reprovações e evasões em 1972

Houve 62 reprovações que representam $2 \%$ dos matriculados no mesmo ano, (3.079) devendo ser enfatizados que $34(62,8 \%)$ efetivaram-se na $1 .^{\mathrm{a}}$ séríe do curso.

As evasões totalizaram 90 ou seja $2,9 \%$ dos matriculados no mesmo ano, sendo as causas familiares $1,1 \%$, casamento $3,3 \%$, desagrado da profissão $5,6 \%$, doença $7,8 \%$, financeiras $8,9 \%$ e causas indeterminadas $73,3 \%$.

Duração do ciclo básico

Responderam 27 escolas $(84,3 \%)$ das quais $2(7,4 \%)$ realizaram c ciclo básico em quatro semestres, $3(11,1 \%)$ em um semestre, 8 $(29,6 \%)$ em três semestres e $14(51,9 \%)$ em dois semestres. 
Graduados em 1972

Das 32 faculdades que responderam, 29 (80,6\%) expediram diplomas em 1972, num total de 722 ou seja 24,8 por faculdade.

Do total de graduados, $38(5,2 \%)$ pertencem ao sexo masculino e $684(94,8 \%)$ ao sexo feminino.

As $15(46,8 \%)$ faculdades que mantiveram $04 .^{\circ}$ ano de Enfermagem em Saúde Pública, expediram 286 diplomas ou seja 19,0 por faculdade, sendo $13(4,6 \%)$ para o sexo masculino e $273(95,4 \%)$ para c feminino.

As $9(28,1 \%)$ faculdades que mantiveram $04 .^{\circ}$ ano de Enfermagem Obstétrica, expediram 95 diplomas ou seja, 10,5 por faculdade, todos para o sexo feminino.

De 1918 a 1972 foram expedidos 11.550 diplomas, sendo 362 $(3,0 \%)$ para o sexo masculino e $11.188(97,0 \%)$ para o sexo feminino.

O número de Enfermeiras (os) de Saúde Pública formados até esta data é de 1194 e o de Enfermeiras Obstétricas, 784.

\section{Licenciatura em Enfermagem}

Em 1972, matricularam-se em cursos de Licenciatura 130 enfermeiras (os), tendo concluido 95, o que dá um total de Licenciados em Enfermagem de 1968 até a presente data de 175.

Das 8 escolas que responderam afirmativamente, seis $\mathbf{( 7 5 , 0 \% )}$ informaram que o curso é totalmente ministrado por Faculdade de Educação.

\section{Revalidação de diplomas}

O número dos diplomas revalidados e a nacionalidade da (os) enfermeiros correspondem às informaçōes de 7 escolas.

Nelas revalidaram seus diplomas: 15 brasileiras, 16 holandesas, 15 americanas, 6 canadenses, 6 francesas, 5 irlandesas, 4 italianas, 4 alemães, 3 inglesas, 2 belgas, 2 espanholas, 1 sueca, 1 escocesa, 1 mexicana, 1 austríaca, 1 suiça, 1 boliviana, 1 da Tchecoslováquia e duas de nacionalidade não identificada, num total de 87 diplomas revalidados.

\section{Mestrado}

Das 23 faculdades que responderam, somente uma ministra o curso. 


\section{Doutoramento}

Recebemos respostas de 22 faculdades, acusando o total de 20 doutoramentos.

\section{Livre-Docência}

Apenas uma Escola possui duas enfermeiras com Livre-Docência.

\section{Corpo Docente}

Para lograr os resultados anteriormente citados, 939 professores foram mobilizados, dos quais $615(65,4 \%)$ são enfermeiras (os), determinando as médias:

Docentes por faculdades: 29,0

Docentes por aluno: 1: 4,5

Docentes enfermeiras por faculdade: 19,2

Docente enfermeira por aluno: 1: 6,9

A evasão de docentes é frequente, pois estão sujeitos a exigências constantes em relação a seu aperfeiçoamento e atualização, não dispõem muitas vezes de material em qualidade e quantidade adequados para o ensino e pesquisa, recebem baixos salários face à sua escolaridade e experiência, tornando difícil aos administradores, conservá-los.

Das 615 docentes enfermeiras (os), 99 (16,1\%) são titulares ou regentes, $64(10,5 \%)$ adjuntos, $166(26,9 \%)$ assistentes e $286(46,5 \%)$ auxiliares de ensino.

O regime semanal de trabalho das docentes enfermeiras varia de: 18 a 24 horas $-210(34,2 \%), 40$ horas - $141(22,9 \%), 12$ horas $78(12,7 \%), 12$ a 17 horas - $78(12,7 \%), 44$ horas - $73(11,8 \%)$, 33 horas $-33(5,4 \%)$ e 36 horas $-2(0,3 \%)$.

O pequeno período em que o docente permanece na faculdade, torna quase impossível a realização de pesquisa, prejudica sensivelmente o ensino, tornando improdutivo o cálculo da relação número de alunos - número de docentes.

\section{CURSOS TECNICOS DE ENFERMAGEM}

As principais características desses cursos são as seguintes:

\section{Localização Geográfica}

Funcionam no momento, 19 cursos Técnicos cie Enfermagem :sendo $12(63,0 \%)$ na região sudeste, $3(16,2 \%)$ na ręião nordes ìe, 
$2(10,4 \%)$ na região sul e $2(10,4 \%)$ na região centro-oeste, inexistindo na região norte.

§ẹecursos utilizados para manutenção

Dos 17 cursos que responderam, $13(76,4 \%)$ são mantidos pur recursos particulares e $4(24,2 \%)$ por recursos públicos, sendo 1 $(25,0 \%)$ federal e $3(75,0 \%)$ estaduais.

Em todos, o sistema de ensino é estadual.

Condições de ingressos, vagas e candidatos

Todos exigem para o ingresso, o término do ginásio, ou seja, da 8. ${ }^{\text {a }}$ série do Curso Fundamental ou de 1.0 Grau.

Em 1973 foram oferecidas 1.214 vagas nos 17 Cursos que responderam, sendo $524\left(43,2 \%\right.$ para a $1 .^{\text {a }}$ série, $387(31,9 \%)$ para a $2 .^{a}$ série e $303(24,9 \%)$ para a $3 .^{a}$ série.

Às 524 vagas da $1 .^{\text {a }}$ série concorreram 780 candidatos, determinando a relação candidato-vaga de $1,4: 1$.

Foram classificados 505 , preenchendo $(96,3 \%)$ das vagas, porém somente $434(82,8 \%)$ matricularam-se.

O percentual de preenchimento das vagas nas diversas séries, pode ser observado no quadro abaixo:

Percentual de preenchimento de vagas nos Cursos Técnicos de Enfermagem, em 1973.

\begin{tabular}{cccccc}
\hline Séries & $\begin{array}{c}\text { Vagas } \\
\text { existentes }\end{array}$ & $\mathbf{H}$ & $\mathbf{M}$ & Total & $\begin{array}{c}\% \\
\text { Preenchimento }\end{array}$ \\
\hline $1 .^{\mathrm{a}}$ & 524 & 59 & 375 & 434 & 82,8 \\
$2 .^{\mathrm{a}}$ & 387 & 29 & 309 & 338 & 87,3 \\
$3 .^{\mathrm{a}}$ & 303 & 9 & 164 & 173 & 57,0 \\
\hline TOTAL & 1.214 & 97 & 848 & 945 & 77,8 \\
\hline
\end{tabular}

A média total de matriculados pcr Curso é de 55,5 e a média de matriculados na $1 .^{\mathrm{a}}$ série é de 25,5.

O percentual de elementos do sexo masculino é de $10,2 \%$ e do sexo feminino $39,8 \%$. 
Reprovações e desistências

As reprovações em 1972 totalizaram 39 alunos $(5,5 \%)$ dos 707 matriculados, sendo $34(87,4)$ na $1 .^{\text {a }}$ série e $5(12,9 \%)$ na $2 .^{a}$ série.

As desistências atingiram 76 alunos o que representa $10,7 \%$ dos matriculados no mesmo ano, sendo $1(1,4 \%)$ por causas familiares, $5(6,7 \%)$ por doenças, $20(26,3 \%$ financeiras, $25(32,8 \%)$ desagrado da profissão e $25(32,8 \%)$ por outras causas não determinadas.

\section{Concluintes}

Em 1972 concluiram o curso 112 técnicos sendo 4 (3,5\%) do sexo masculino e $108(96,5 \%)$ do feminino, dando a média de concluintes por Curso de $\mathbf{7 , 4}$.

Foram expedidos até 1972, 423 certificados de técnicos de enfermagem, sendo $15(3,5 \%)$ a elementos do sexo masculino e $408(96,5 \%)$ a elementos do sexo feminino.

Corpo docente

Ministram aulas nos 15 cursos que responderam, 213 docentes, sendo $86(40,3 \%)$ enfermeiras (os), com a média de 50 docentes enfermeiras (os) por curso e a relação docente enfermeira (o) por aluno de $1: 10,5$.

O regime semanal de trabalho das docentes enfermeiras é de: 44 horas $23(26,7 \%), 18$ a $24-18(20,9 \%), 24$ a 33 horas -16 $(18,6 \%),-12$ horas - $13(15,1 \%), 12$ a 17 horas $-8(9,4 \%), 40$ horas $-6(6,9 \%), 36$ horas $-1(1,2 \%)$ e 33 horas $-1(1,2 \%)$.

\section{CURSOS DE AUXILIAR DE ENFERMAGEM}

Em 1972 funcionaram 94 Cursos de Auxiliar de Enfermagem, encontrando-se fechados ou em recesso os CAE da EE, Santa Casa de Campos (RJ), da EE da Universidade Federal Fluminense (RJ), da EE Wenceslau Braz (MG), Frei Eugênio (MG), Delta (SP), Bráulio Gomes (SP), e da EE Universidade Federal do Rio Grande do Sul (RS) .

\section{Localização Geográfica}

Os Cursos localizam-se: $51(54,3 \%)$ na região sudeste, $20(21,3 \%)$ na região sul, $15(15,9 \%)$ na região nordeste, $6(6,4 \%)$ na região centro-oeste e $2(2,1 \%)$ na região norte. 
Não existe curso de auxiliar de enfermagem nos Estados do Acre e Pará e nos Territórios.

Recursos utilizados para manutenção

$60(67,4 \%)$ cursos são mantidos por recursos particulares e 29 $(32,6)$ por recursos públicos, sendo $4(4,5 \%)$ municipais, $9(10,2 \%)$ federais e $16(17,9 \%)$ estaduais.

O sistema de ensino varia, sendo $21(23,6 \%)$ federal e $63(76,4 \%)$ estadual.

\section{Duração do Curso}

$60(67,4 \%)$ cursos têm a duração de 2 anos e $29(32,6 \%) \mathrm{mi}$ nistram o curso em 11 meses.

Condições de ingresso, vagas e candidatos

Existe disparidade de exigências para o ingresso no curso de auxiliar de enfermagem: em $35(39,4 \%)$ é exigido ginásio completo, cu seja a 8. ${ }^{a}$ série Fundamental ou de $1^{\circ}$ gráu em $22(24,7 \%)$ a 2. ${ }^{\text {a }}$ série ginasial, ou seja, a $6 .^{a}$ série, do curso fundamental ou de 1. gráu, em $10(11,2 \%)$ apenas o primário completo e $22(24,7 \%)$ não informaram.

Em 1973 foram oferecidas 5.532 vagas, sendo $3.328(60,1 \%)$ para a $1 .^{a}$ série e $2.204(39,9 \%)$ para a $2 .^{a}$ série.

As 3.328 vagas da $1 .^{\mathrm{a}}$ série, concorreram 9.461 candidatos, determinando a relação candidatos por vaga de 2, 2:1.

Foram classificados 4.544 , porém somente 3.440 matriculam-se.

O percentual de preenchimento das vagas nas diversas séries, pode ser observado no quadro abaixo:

Percentual de preenchimento de vagas nos Cursos de Auxiliar de Enfermagem, em 1973.

\begin{tabular}{llcccc}
\hline Séries & Vagas & \multicolumn{3}{c}{ Matriculados } & $\%$ \\
\hline $1 .^{\mathrm{a}}$ & 3.328 & 499 & 2.941 & 3440 & $103,3 \%$ \\
$2 .^{\mathrm{a}}$ & 2.204 & 318 & 1.885 & 2.203 & $99,9 \%$ \\
\hline TOTAL & 5.532 & 817 & 4.826 & 5.643 & $102,0 \%$ \\
\hline
\end{tabular}

A média total de matriculados por curso é de 63,4 . 
Dos matriculados no $1 .^{\circ}$ ano, $2.146(62,3 \%)$ são de cursos de 2 anos, sendo $1.786(83,2 \%)$ do sexo feminino e $360(16,8 \%)$ do sexo masculino, $1.294(37,7 \%)$ são de curso de 11 meses, sendo 1.155 $(89,2 \%)$ do sexo feminino e $139(10,8 \%)$ do sexo masculino.

Do total de matriculados $5.643,817(14,4 \%)$, pertencem ao sexo masculino e $4.826(85,6 \%)$ ao feminino.

\section{Reprovações e desistências}

Foram reprovados em 1972, 231 alunos $(6,4 \%)$ dos $4.278 \mathrm{ma}-$ triculados.

As desistências atingiram 493 alunos que representam 11,5\% dos matriculados no mesmo ano, sendo $19(3,8 \%)$ por casamento, 22 $(4,4 \%)$ por causas familiares, $38(7,7 \%)$ por doenças, $41(8,4 \%)$ por causas financeiras, $61(12,4 \%)$ por desagrado da profissão e 312 $(63,3 \%)$ por causas não determinadas.

\section{Concluintes}

Em 1972 concluiram o curso 2.506 auxiliares, sendo $280(11,0 \%)$ do sexo masculino e $2.226(88,9 \%)$ do sexo feminino, dando a média de 28,9 concluintes por curso.

Foram expedidos até 1972, 25.610 certificados de auxiliar de enfermagem sendo $2.262(8,8 \%)$ a elementos do sexo masculino e $23.348(91,2 \%)$ a elementos do sexo feminino.

\section{Corpo docente}

Ministraram aulas nos 89 cursos que responderam, 827 professores, sendo $582(69,8 \%)$ enfermeiras (os), com a média de 6,5 docentes enfermeiras (os) por curso e a relação docente enfermeira (o) por aluno de $1: 9,0$.

O regime semanal de trabalho das docentes enfermeiras (os) é de 18 a 24 horas - $168(29,1 \%), 44$ horas - $119(20,5 \%),-12$ horas $106(18,3 \%), 40$ horas $-93(15,9 \%), 33$ horas $-58(9,9 \%)$, 36 horas $-23(3,9 \%), 12$ a 17 horas $-14(2,4 \%)$.

\section{OS PROFISSIONAIS DE ENFERMAGEM EM ALGUNS} ESTADOS DA FEDERAÇÃO

Como resultado da tentativa de obter informações sobre algumas características do exercício profissional, obtivemos resposta de 12 $(54,5 \%)$ Seções Estaduais da ABEn e 2 (40,0\%) das Secretarias de Saúde, abrangendo 13 Estados e um Território $(53,8 \%)$. Percentual 
tão baixo de respostas demonstra a inexistência de dados scbre pessoal de enfermagem nos diversos estados. Por outro lado, como poderemos executar planos realistas de assistência de enfermagem, se não sabemos exatamente qual o recurso humano disponivel?

Responderam os seguintes estados: Pará, Piauí, Paraíba, Alagoas, Bahia, Minas Gerais, Rio de Janeiro, Guanabara, Paraná, Santa Catarina, Maranhão, Mato Grosso, Espírito Santo e Território de Amapá.

O levantamento realizado indica, no conjunto desses estados, a existência de 4.289 enfermeiros, 159 técnicos de enfermagem e 10.010 auxiliares de enfermagem, exercendo a profissão.

Na Guanabara existem $1.950(45,5 \%)$ enfermeiras, em Minas Gerais $928(21,6 \%)$, Bahia $381(8,9 \%)$, Rio de Janeiro $293(6,9 \%)$, Pará $186(4,3 \%)$, Paraná $133(3,1 \%)$, Paraíba $123(2,9 \%)$, Maranhão 92 $(2,1 \%)$, Santa Catarina $91(2,1 \%)$, Piauí $32(0,8 \%)$, Alagcas 25 $(0,6 \%)$, Mato Grosso $23(0,5 \%)$, Espírito Santo $22(0,5 \%)$ e Amapá $10(0,2 \%)$.

Excluindo a Guanabara que possui 1.950 (45.5\%) enfermeiros, trabalhando em área urbana por constituir um Estado-Cidade, os $2.339(54,5 \%)$ enfermeiros distribuidos pelos outros Estados, localizam-se $1.846(78,9 \%)$ em capitais e $493(21, \%)$ no interior.

Do total de enfermeiros das instituições (4.289), $2.503(58,4 \%)$ trabalham em hospitais gerais, $716(16,7 \%)$ em Saúde Pública e 225 $(5,2 \%)$ em hospitais de tuberculose, 157 (3,7\%) em maternidades, $76(1,7 \%)$ em hospitais psiquiátricos, $15(0,4 \%)$ em hospitais de lepra e $597(13,9 \%)$ em escolas.

Os técnicos de enfermagem encontram-se distribuídos $\mathrm{em}$ hospitais gerais $75(47,1 \%)$, em maternidades $31(19,4 \%)$, nos hospitais de tuberculose $11(6,9 \%)$, hospitais psiquiátricos $8(5,3 \%)$ e em Saúde Pública $34(21,3 \%)$.

Na Guanabara existem $100(62,5 \%)$ técnicos, no Paraná 50 $(31,5 \%)$, Rio de Janeiro $4(2,7)$, em Santa Catarina $3(1,9 \%)$, na Paraíba $1(0,7 \%)$, em Minas Gerais $1(0,7 \%)$, inexistindo no Pará, Maranhão, Piauí, Alagoas, Bahia, Mato Grosso, Espírito Santo e Amapá.

Os auxiliares de enfermagem encontram-se distribuidos em hospitais gerais $8.205(81,9 \%)$, em hospitais de tuberculose $611(6,1 \%)$, em maternidades $518(5,2 \%)$, em Saúde Pública 488 (4,9\%), em hospitais psiquiátricos $158(1,6 \%)$ e em hospitais de lepra $30(0,3 \%)$.

Na Guanabara existem $5.172(51,7 \%)$ auxiliares, em Minas Gerais $1.816(18,1 \%)$, na Bahia $537(5,4 \%)$, no Paraná $500(5,0 \%)$, no Pará $482(4,8 \%)$, no Rio de Janeiro $324(3,2 \%)$, na Paraíba 284 $(2,8 \%)$, em Santa Catarina $238(2,4 \%)$, em Mato Grosso $220(2,2 \%)$, 
no Maranhão $180(1,8 \%)$, em Alagoas $129(1,3 \%)$ e no Piauí, 128 $(1,3 \%)$. O Território do Amapá não informou e o Estado do Espírito Santo incluiu atendentes e auxiliares de serviços médicos, razão pela qual não podemos apreciar.

Outras informações que constavam do questionário, como salário mínimo e máximo na região e preparo do corpo docente das escolas, não serão aqui analisadas porque os dados obtidos não foram significativos.

\section{CONCLUSÕES}

- Atenção deve ser dirigida para a precariedade de nossos sistemas de registros, que impossibilita a determinação do número exato de profissionais de enfermagem que concluiram seus cursos e existentes no campo de trabalho, diminuindo as possibilidade de real e efetivo planejamento das atividades de enfermagem.

- O congestionamento numérico de profissionais de enfermagem nos grandes centros urbanos e capitais, ocasionado pela procura de maiores e melhores oportunidades, continua dificultando a sua interiorização.

- O atual número de profissionais de enfermagem, não atende às necessidades de saúde do país, não só em relação ao número total como pela inadequada proporção entre os três tipos de profisisonais.

- Tem havido aumento gradual de candidatos e concluintes nas escolas de enfermagem, de técnicos e de auxiliares de enfermagem

- Os cursos técnicos de enfermagem vêm se firmando no sistema de ensino, com a criação de novos cursos em diversas regiões do país.

- Os cursos de auxiliar de enfermagem, apesar da diminuição numérica ou talvez devido a ela, tornaram-se mais produtivos, concentrando maior número de alunos e de docentes e de certificados expedidos. 


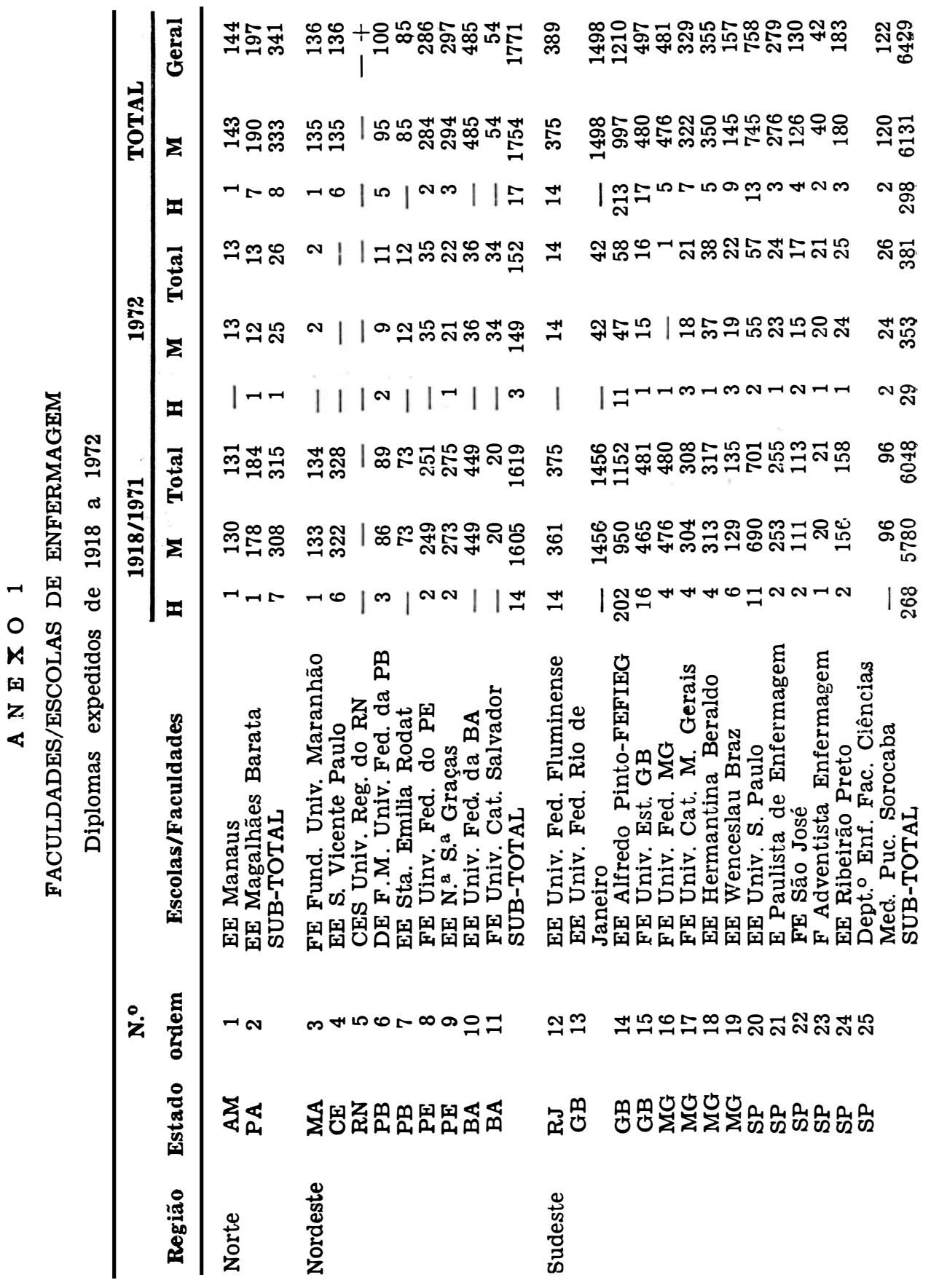




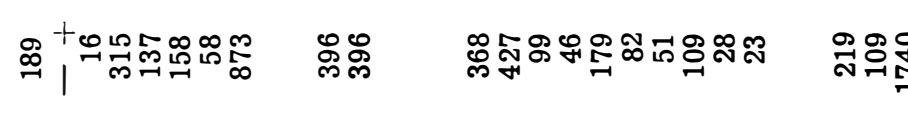

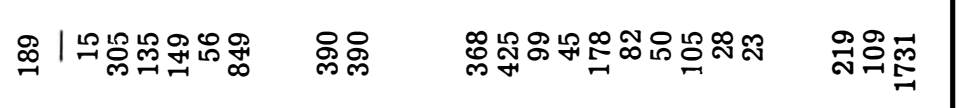

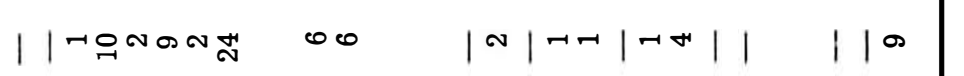

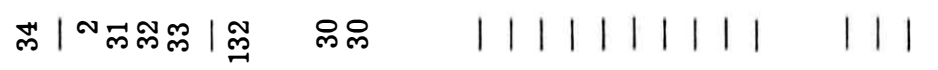

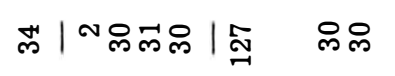

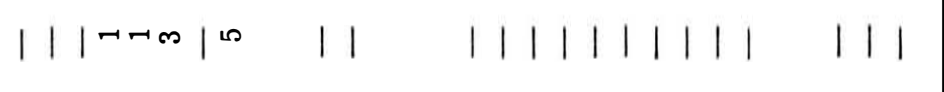

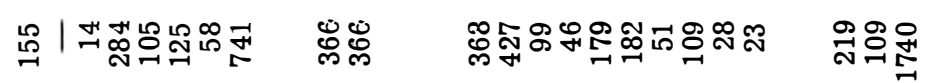

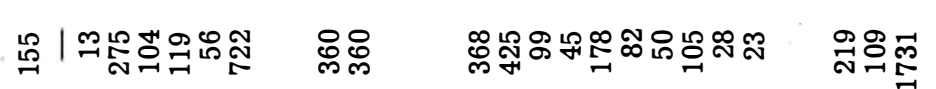
| | |

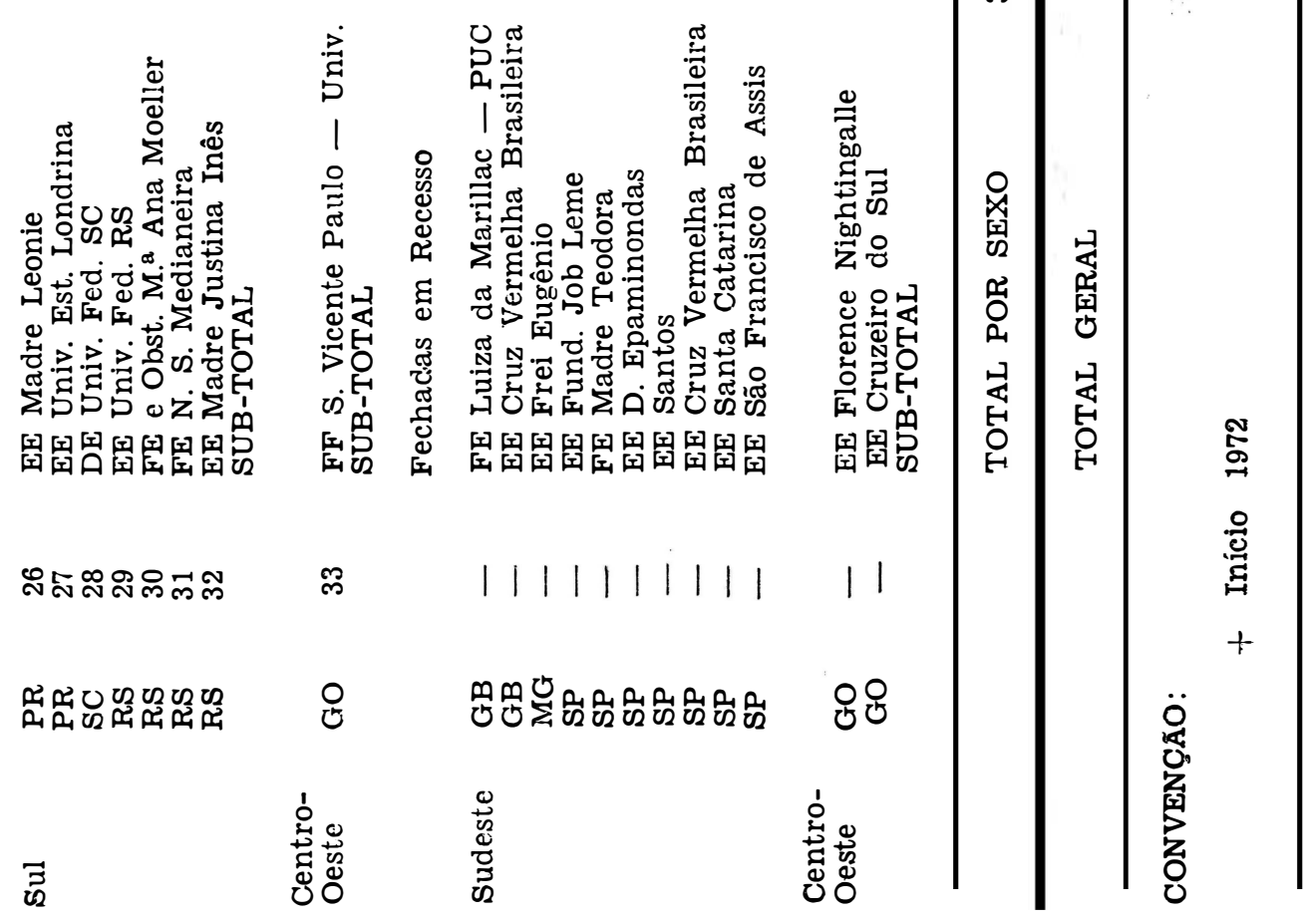




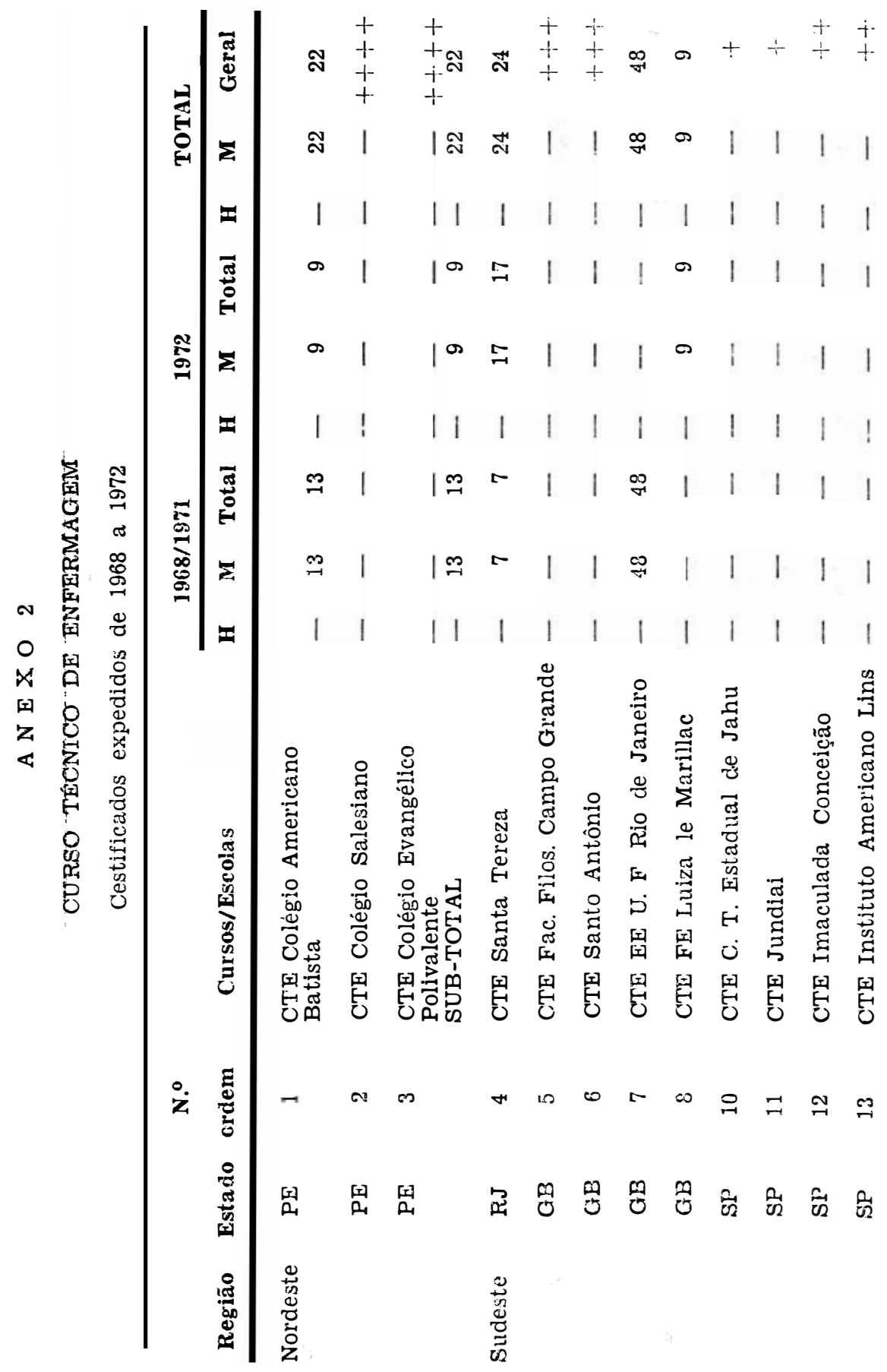




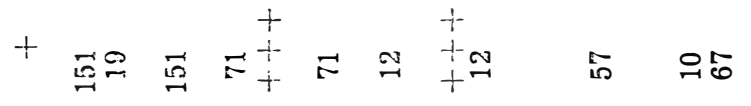

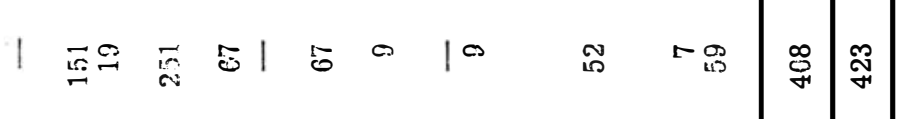

$$
\begin{aligned}
& 1|1| \pi \mid \begin{array}{llllll}
1 & 10
\end{array}
\end{aligned}
$$

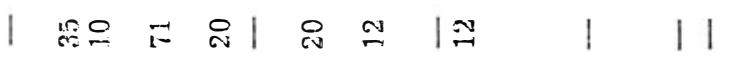

$$
\begin{aligned}
& \text { | } \\
& |1| 1-1+\infty \mid \begin{array}{lll}
1 & 1 & 1
\end{array}
\end{aligned}
$$

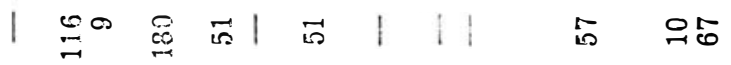

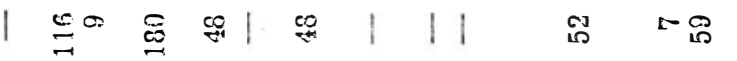

$$
\begin{aligned}
& |1||m|=|1| \text { in } m
\end{aligned}
$$

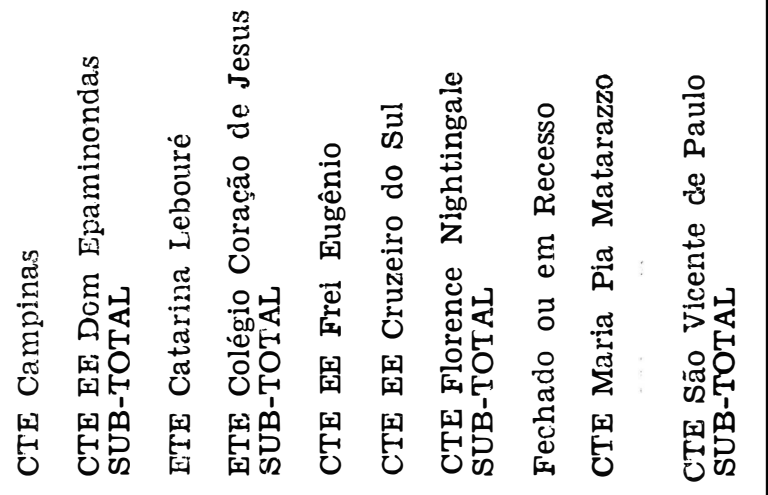

$$
\begin{aligned}
& \text { 承 } \\
& 2
\end{aligned}
$$

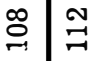

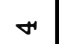

$$
\begin{aligned}
& \text { 六 } \\
& \approx
\end{aligned}
$$

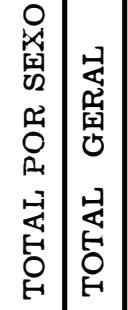

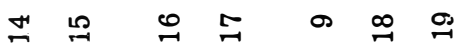

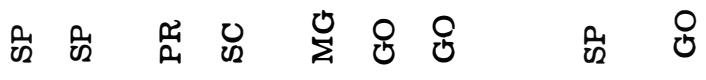

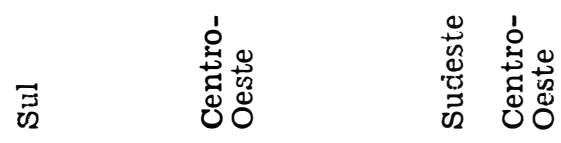




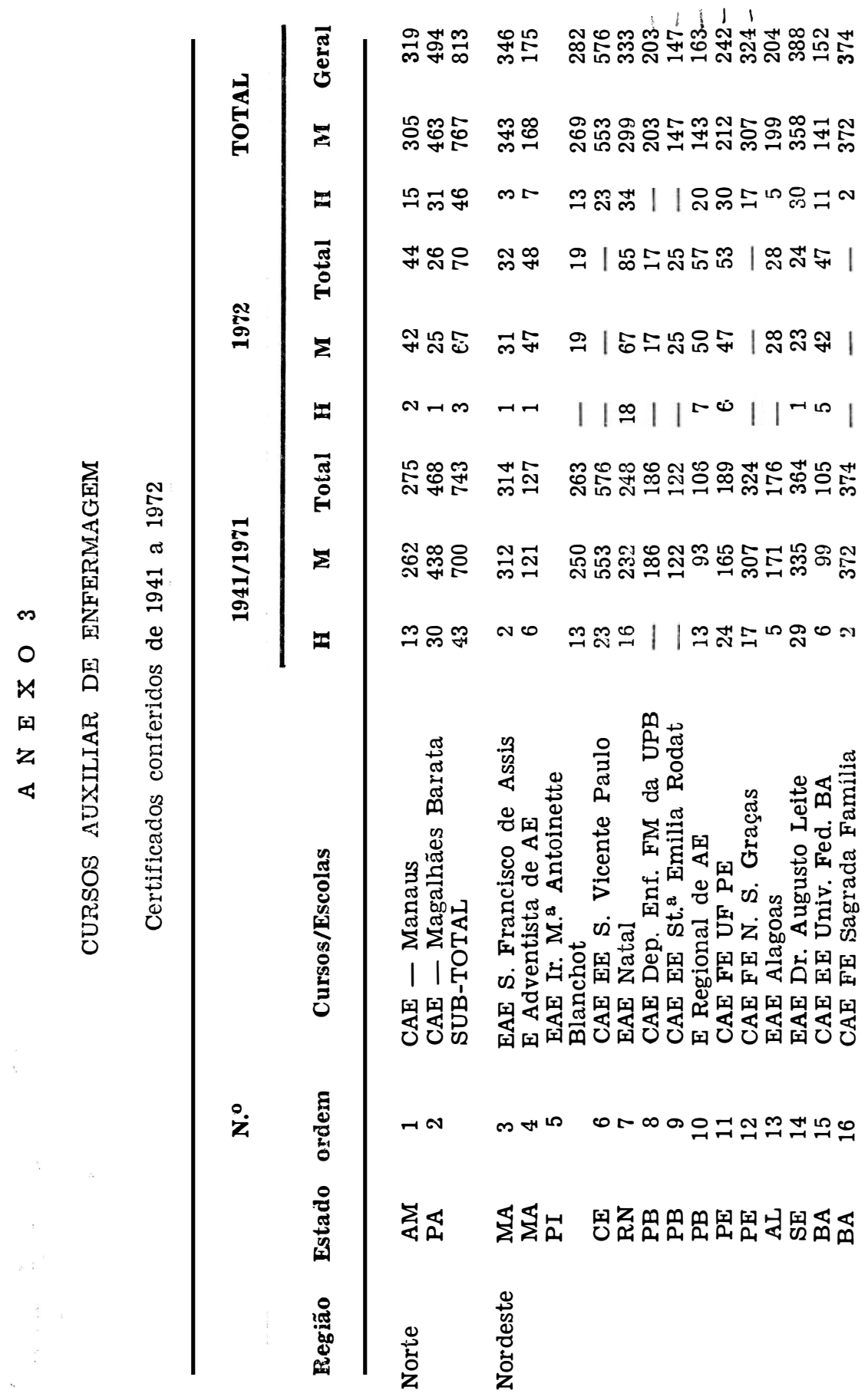




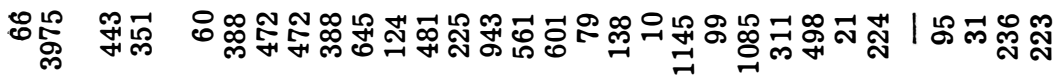

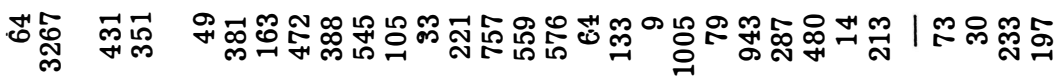

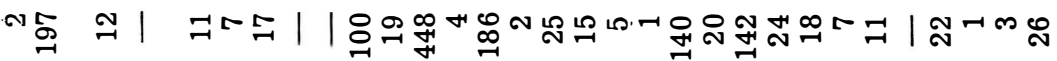

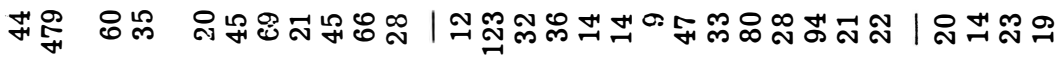

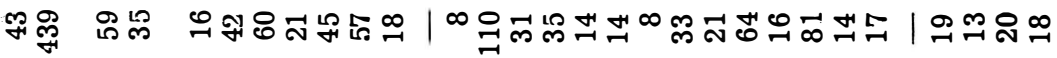

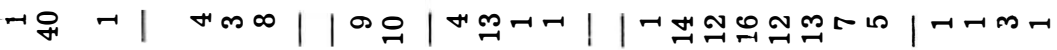

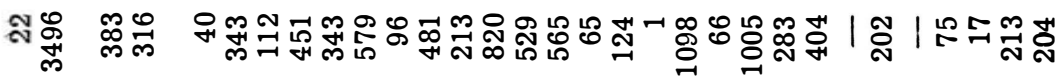

స్స్ల్ల

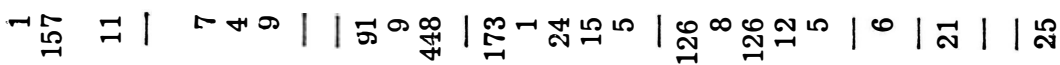

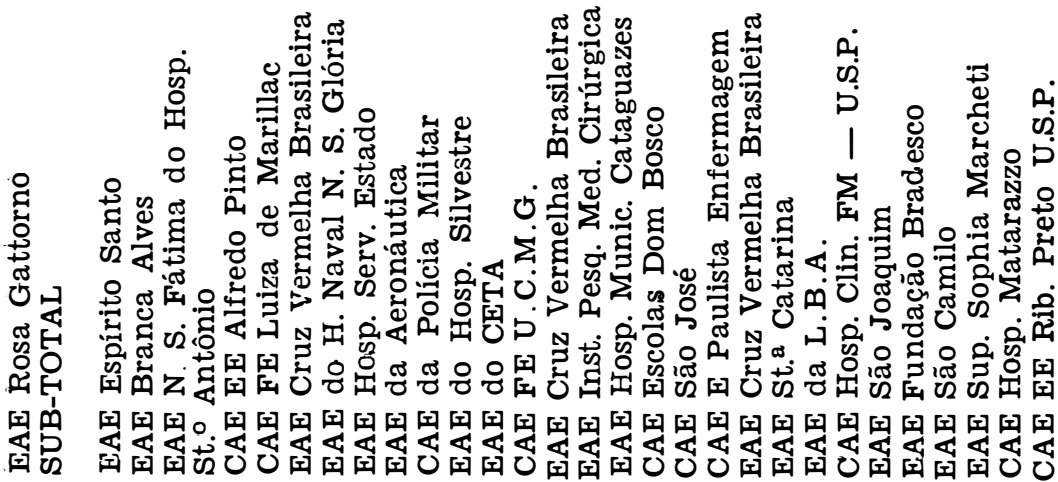

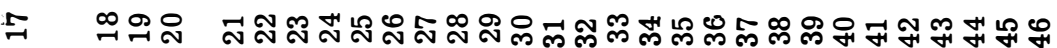

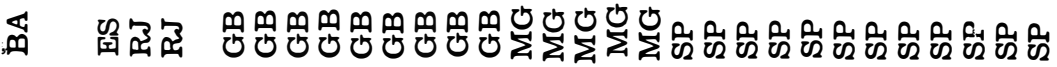

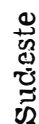




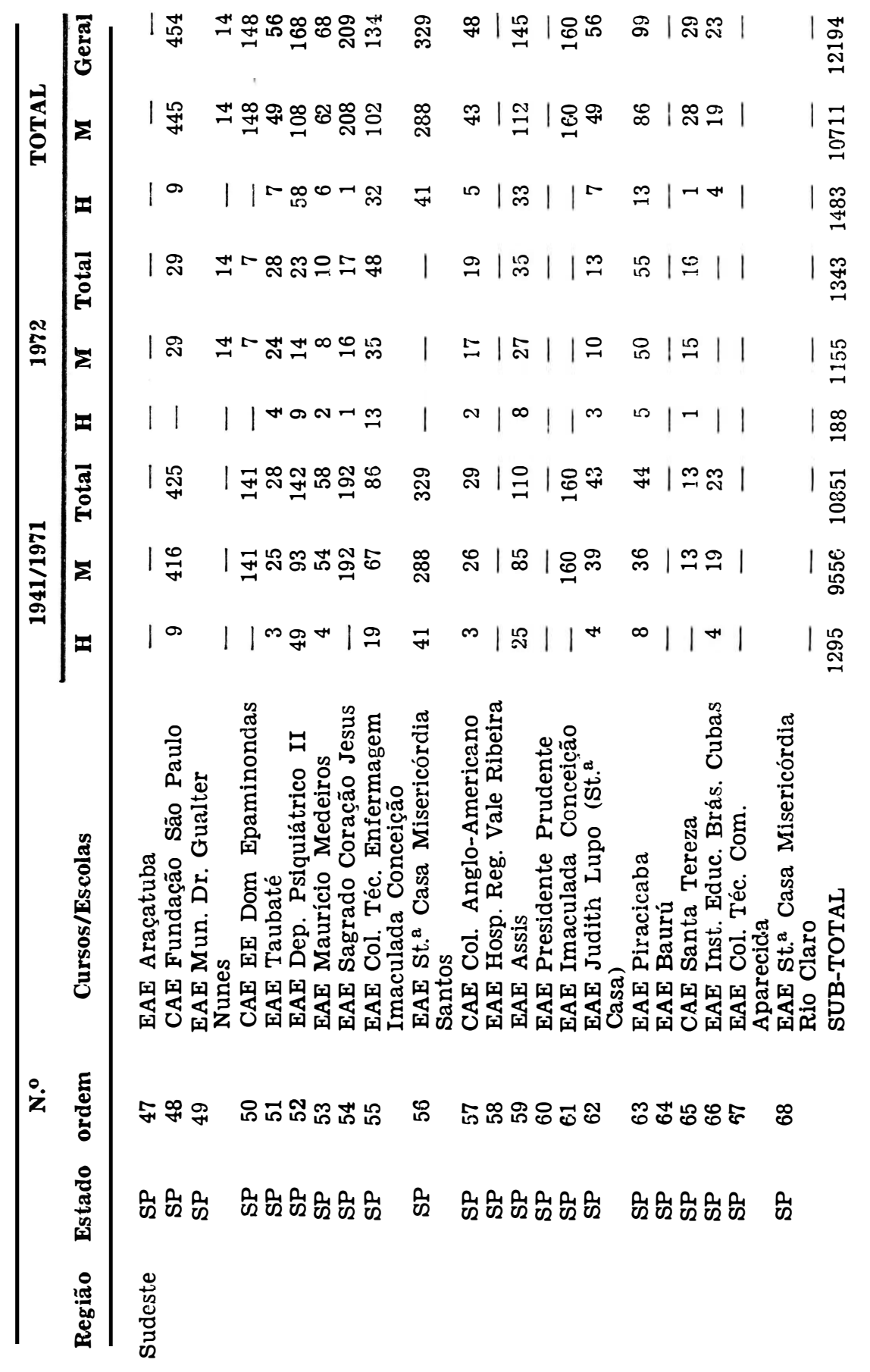




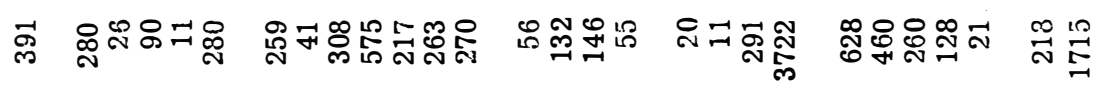

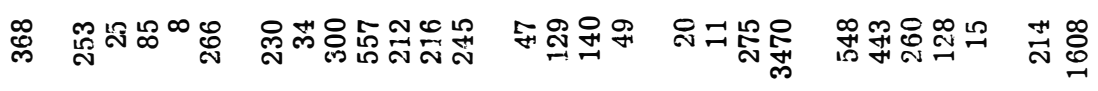

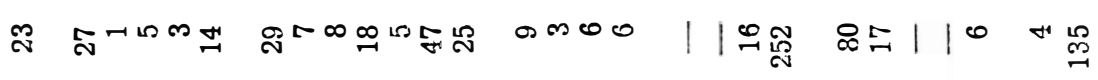

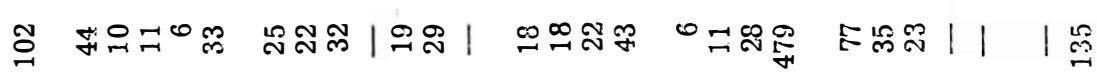

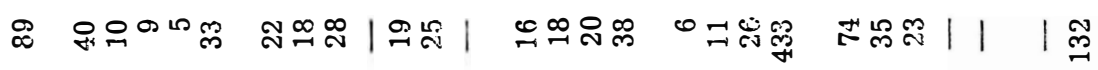

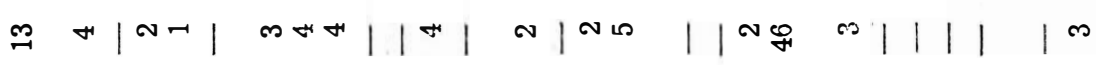

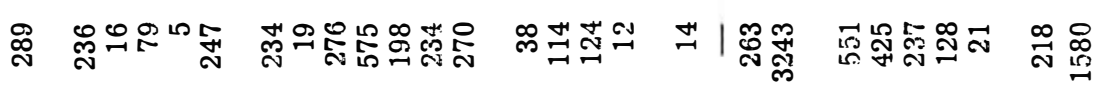

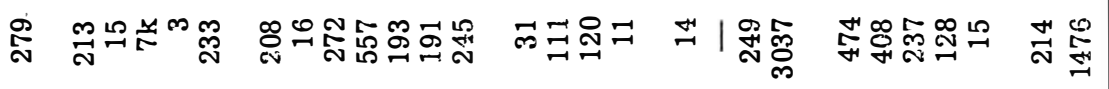

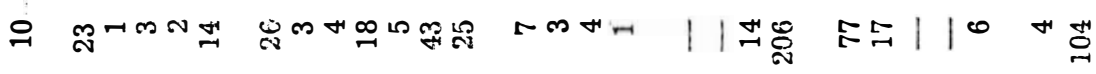

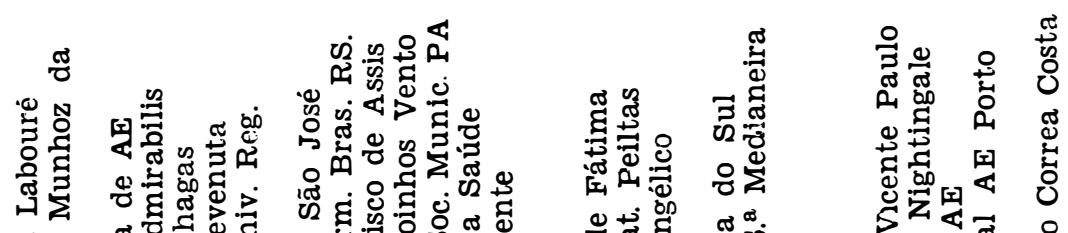

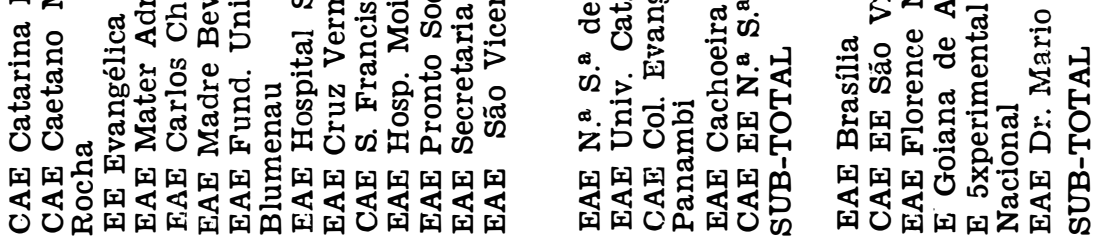

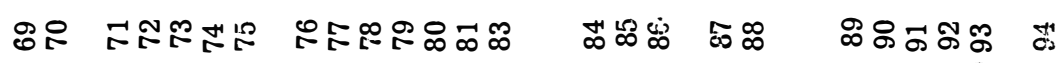

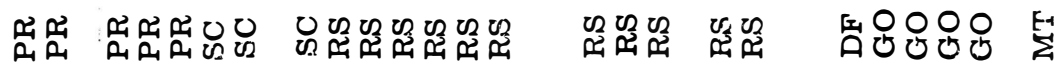




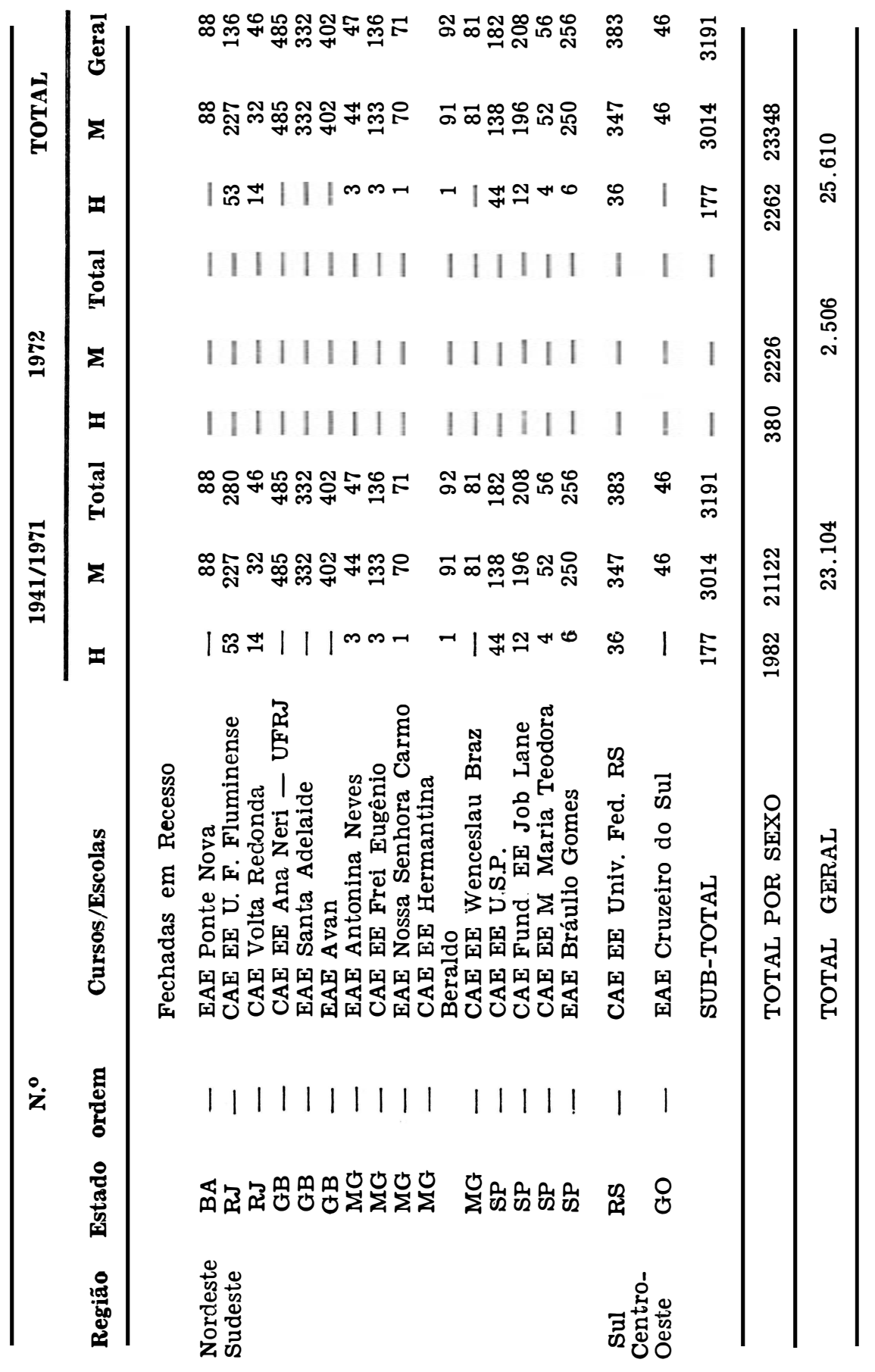




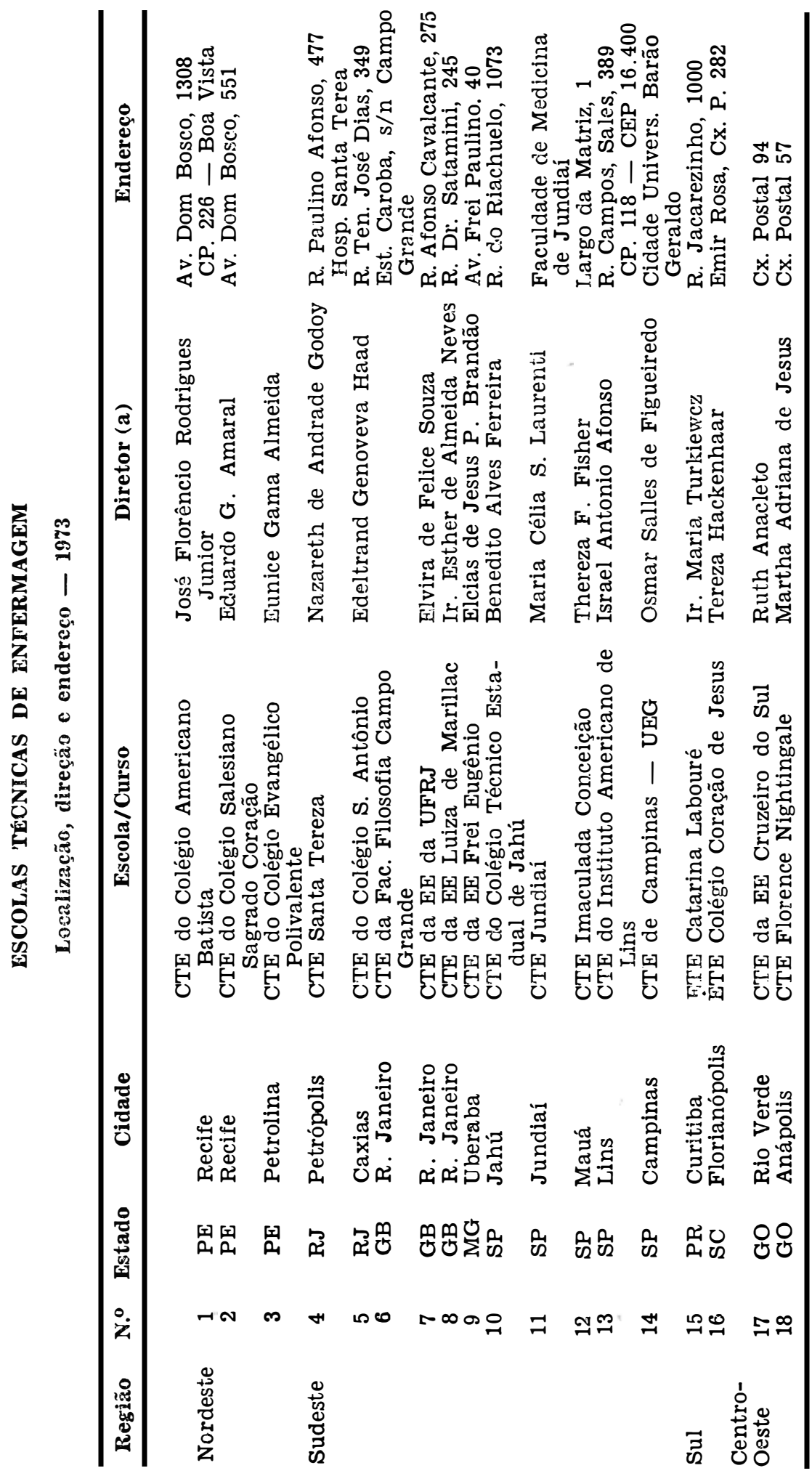




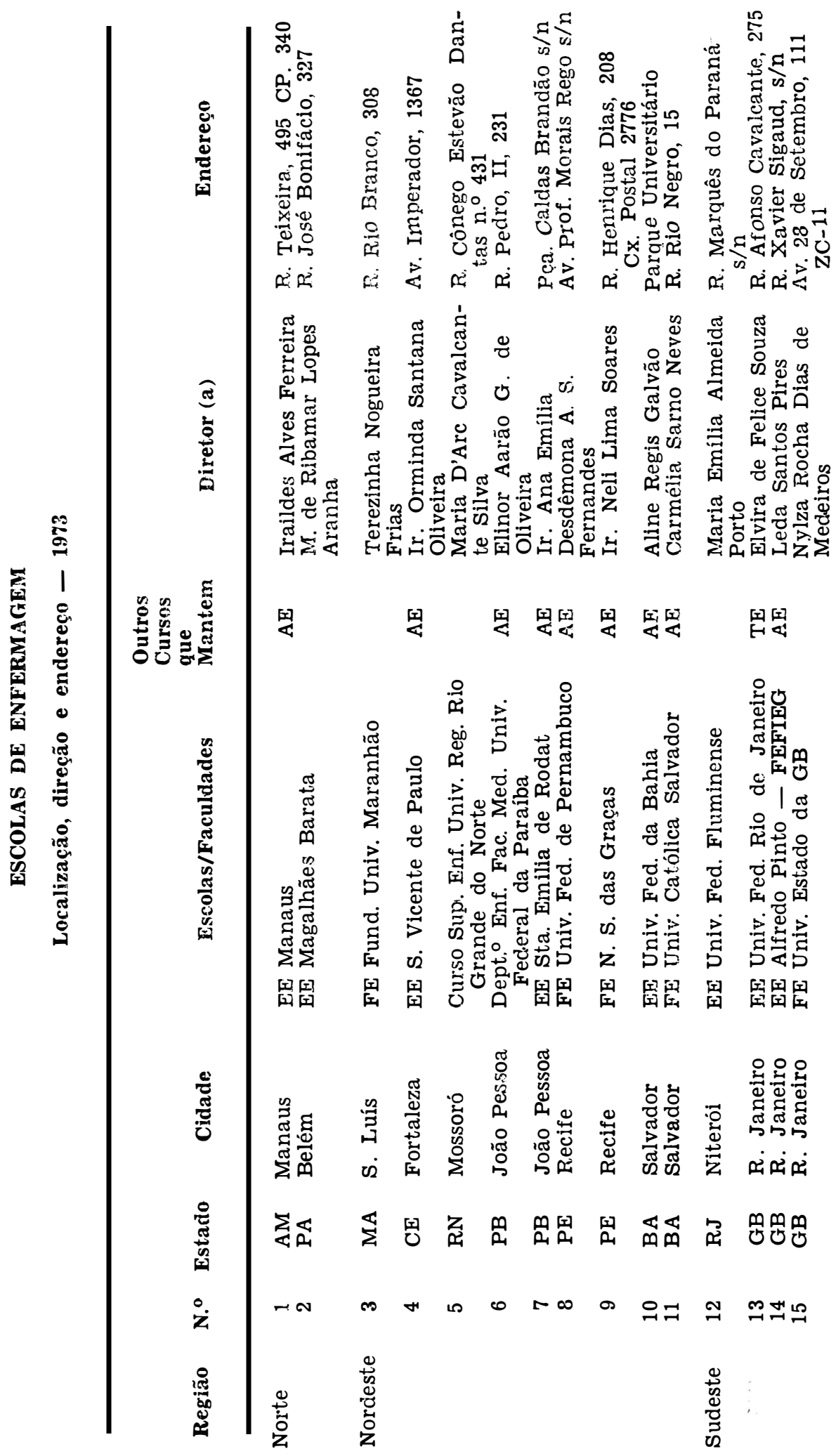




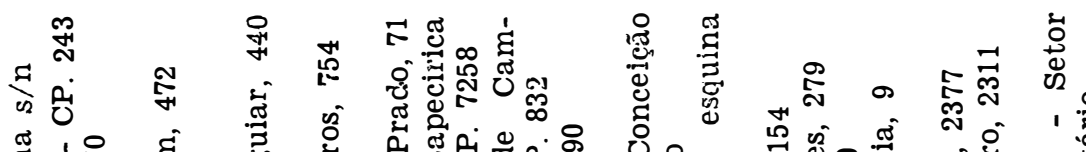

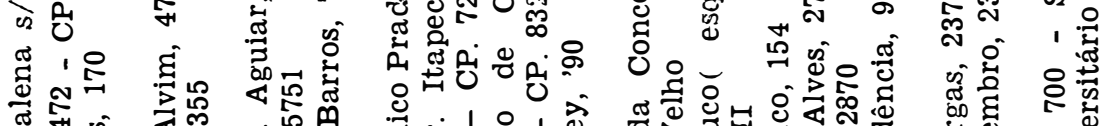

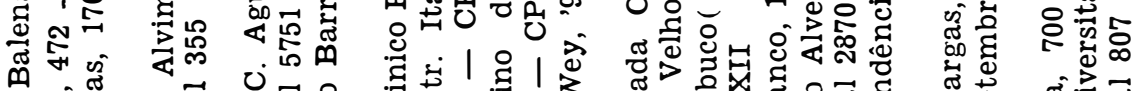

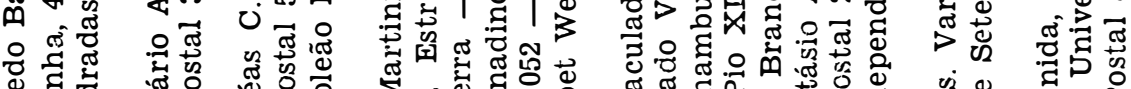

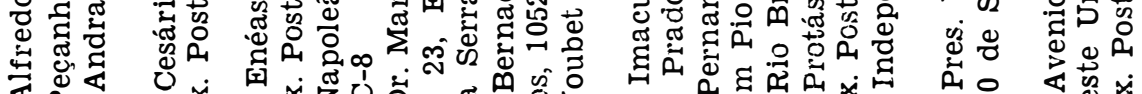

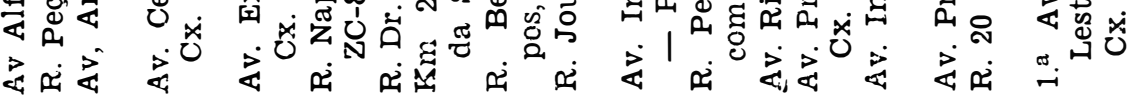

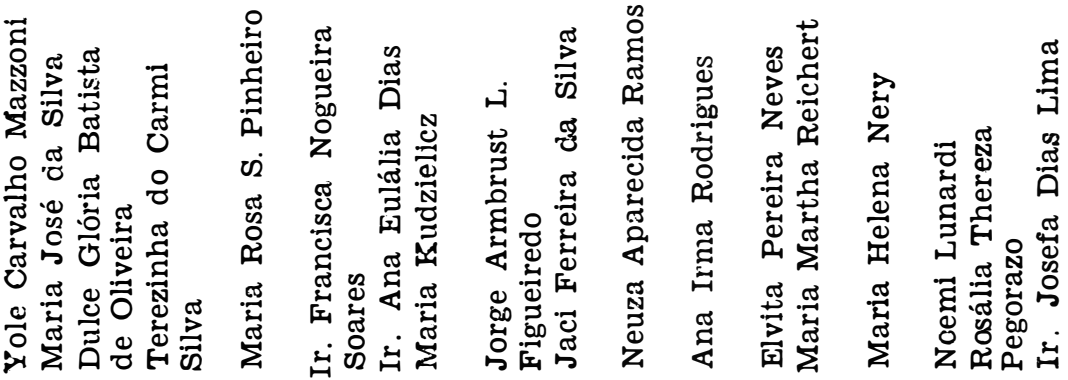

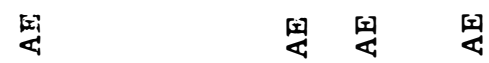

늘

형 ㅎํㅇㅇㅡ

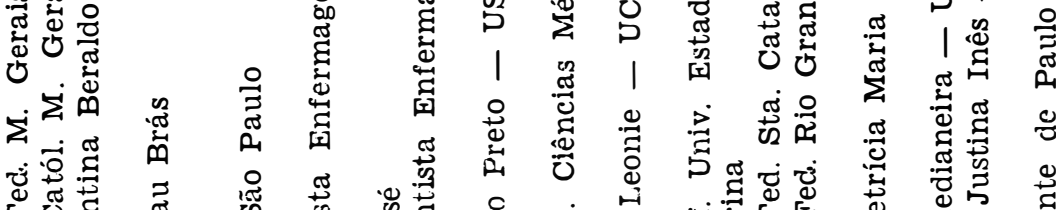

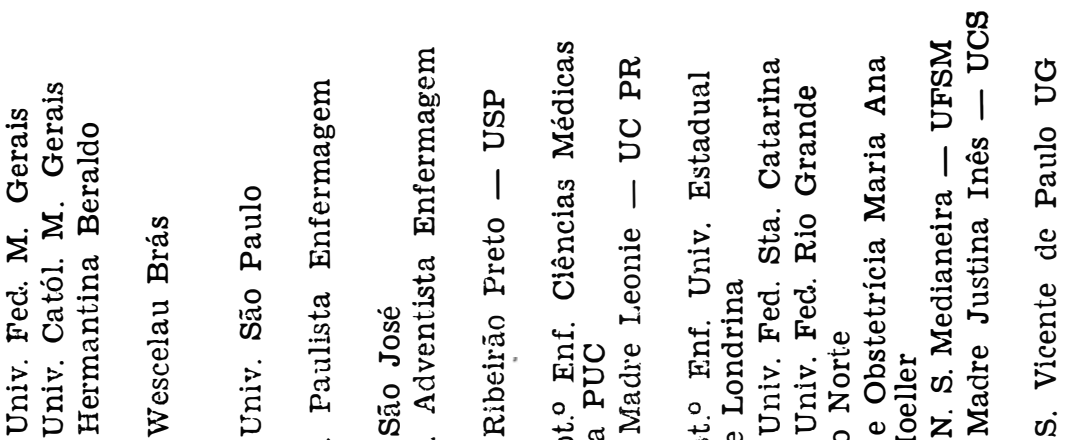

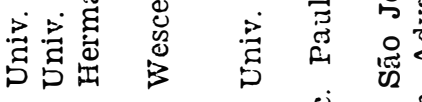

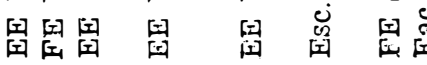

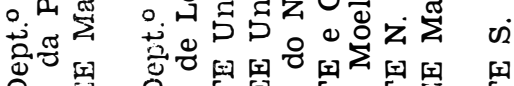

藏

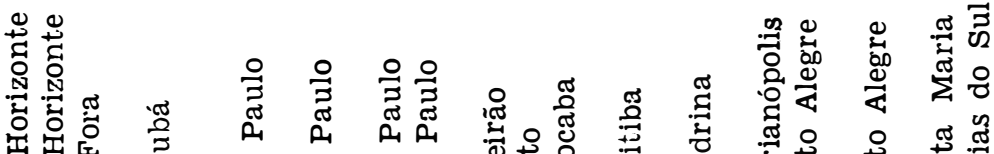

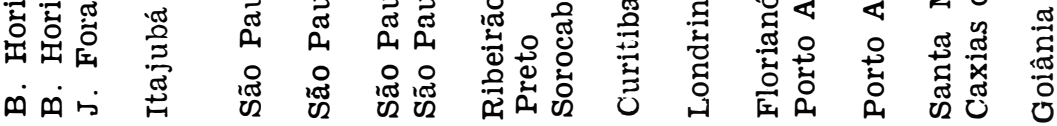

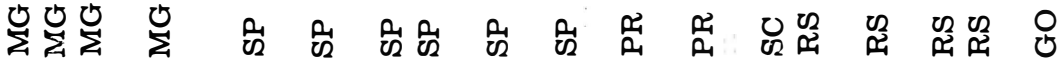

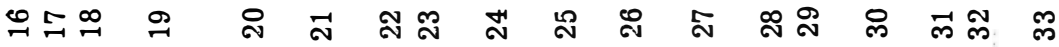




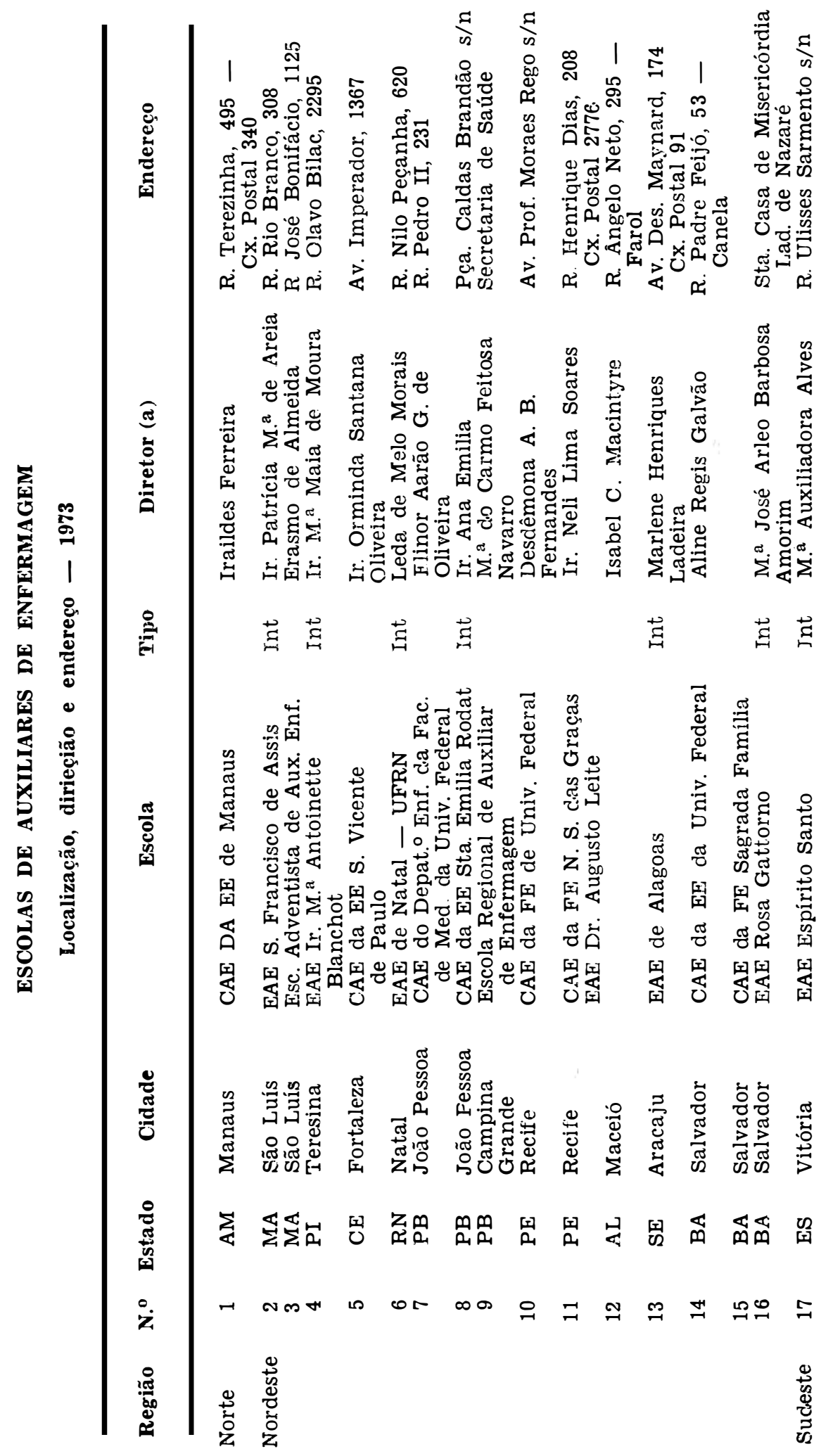




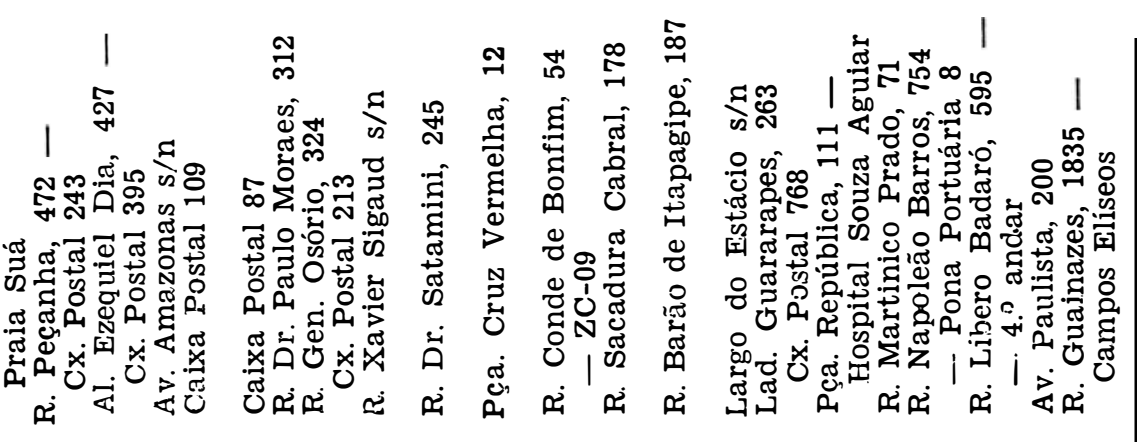

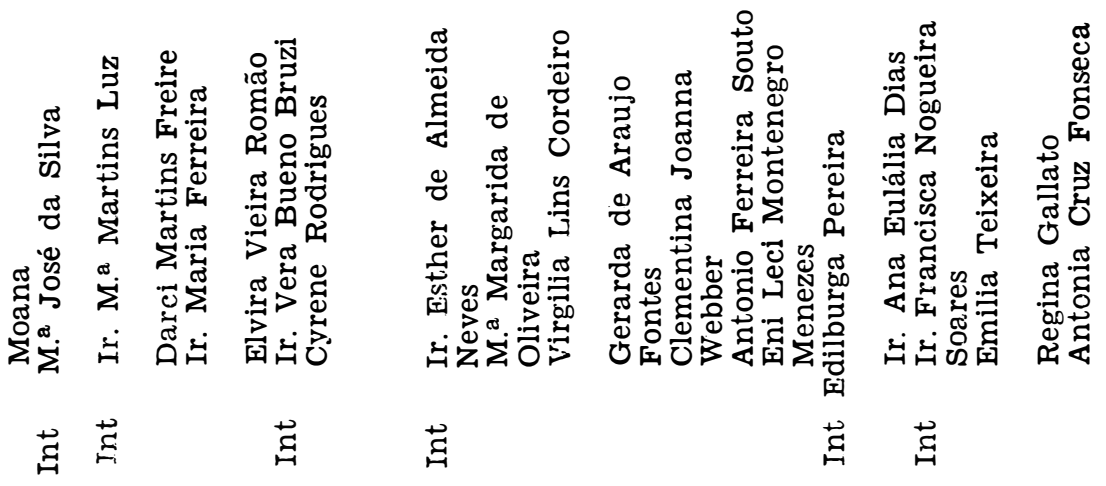

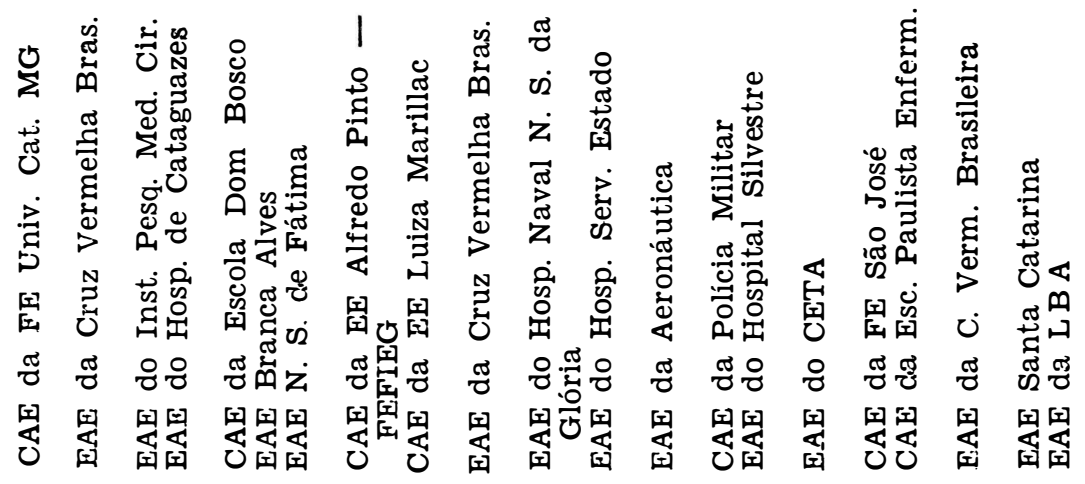

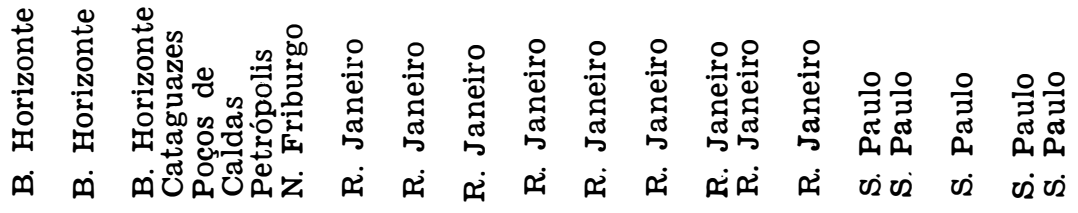

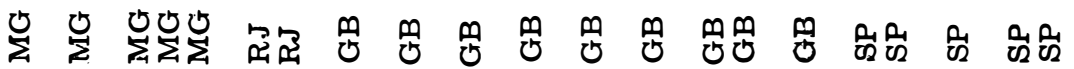

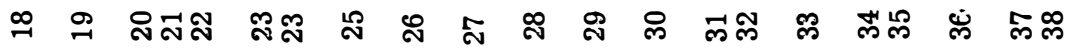




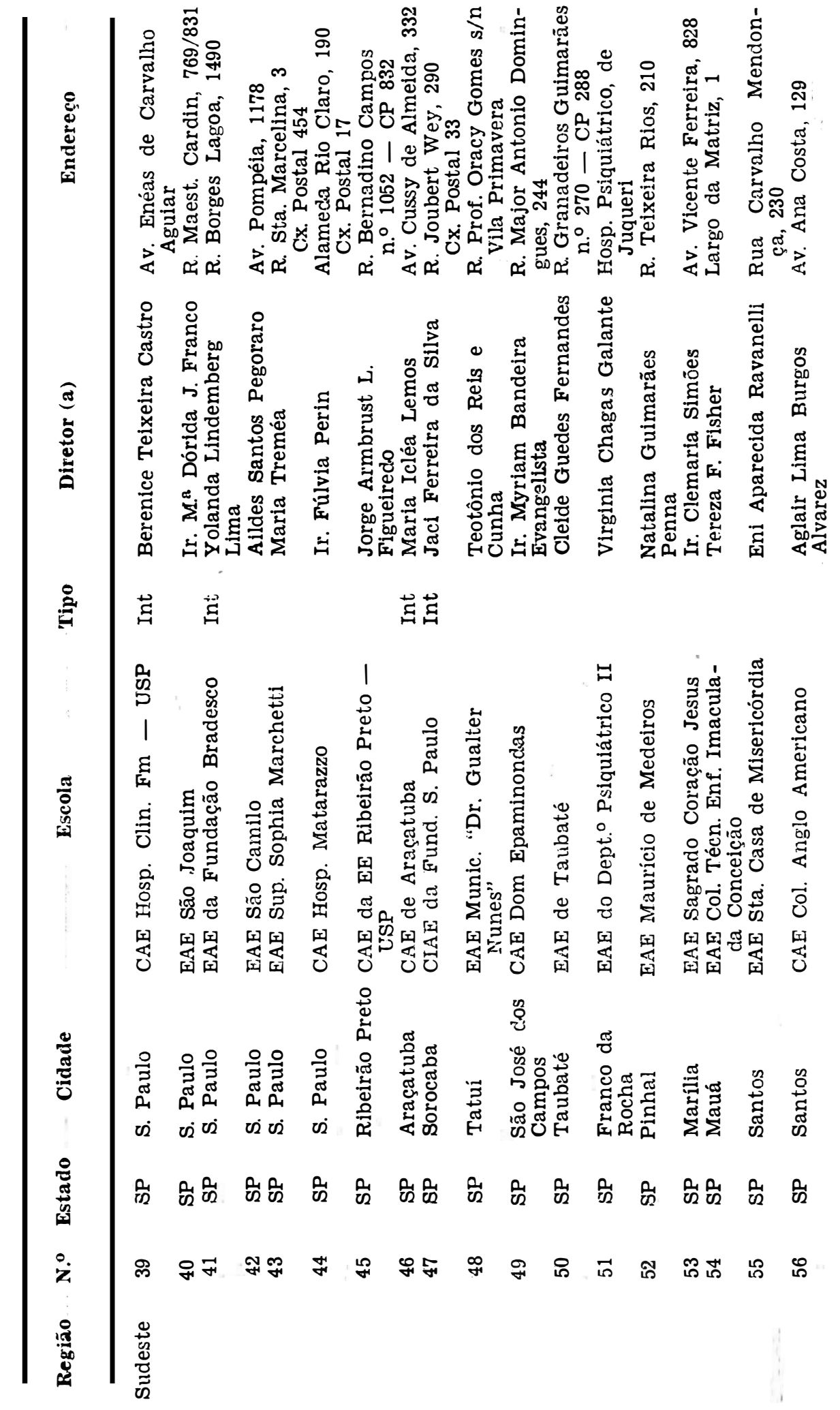




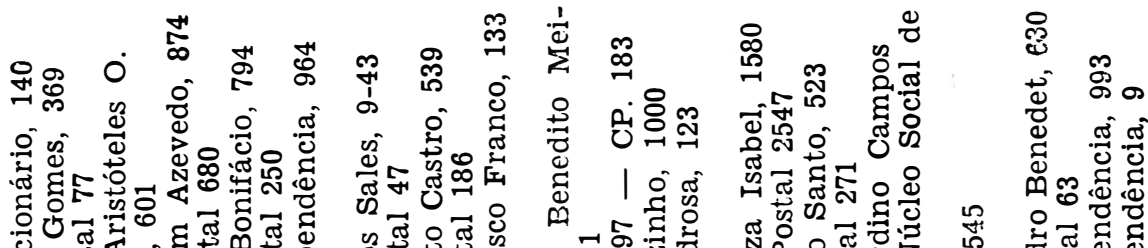

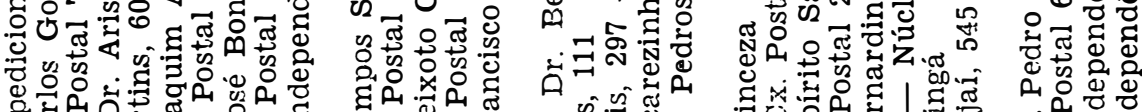

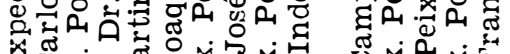

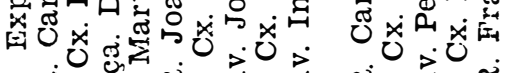

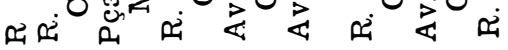
(5)

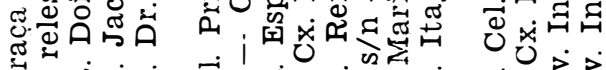

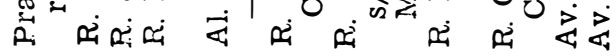

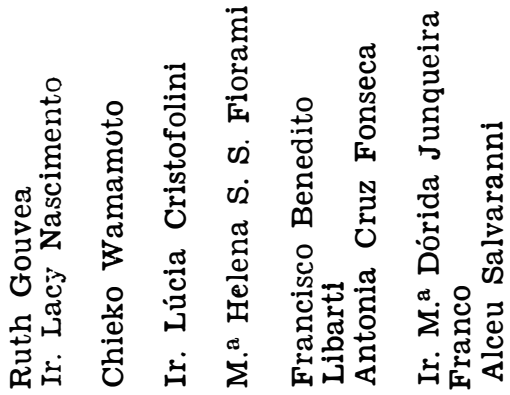

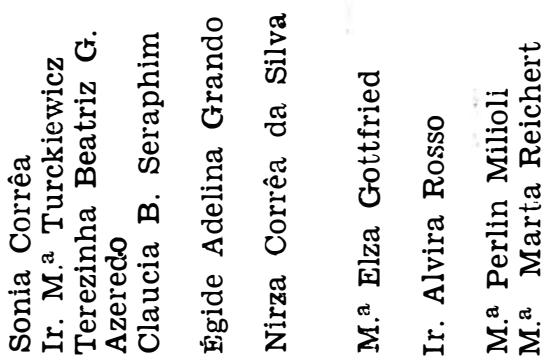
芯 芯

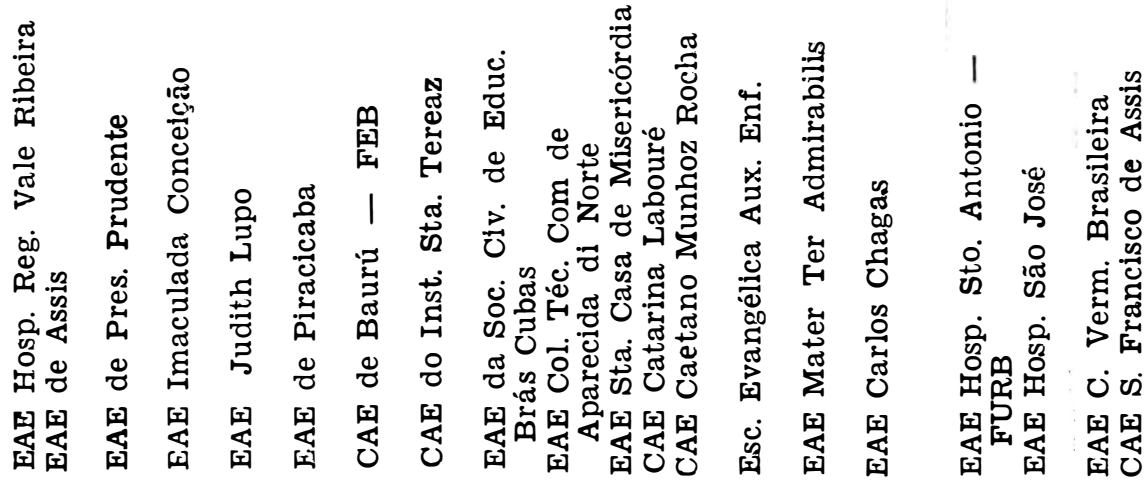

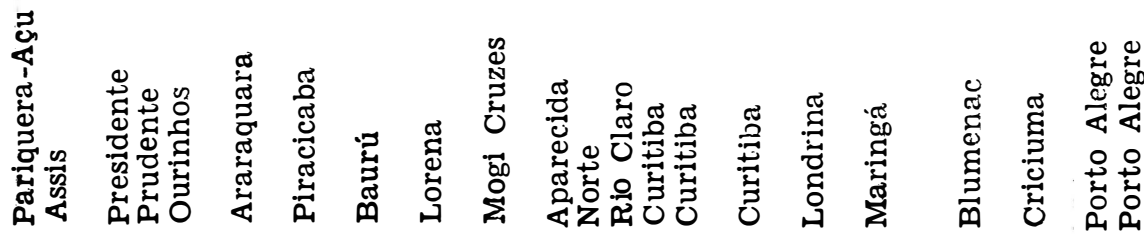

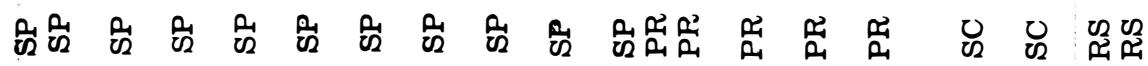
เท็一ำ 


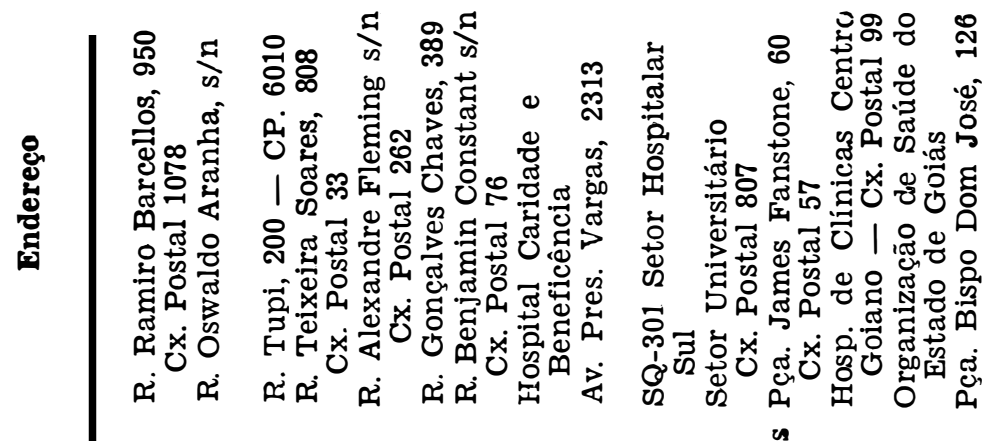

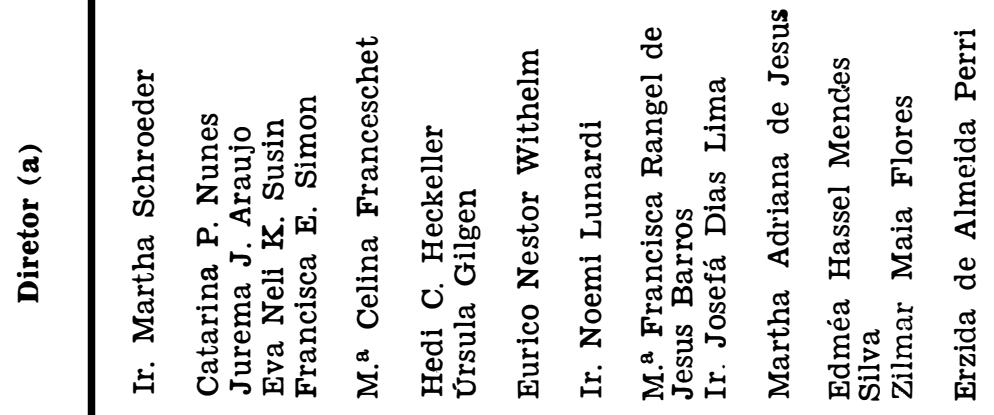

总

$\underset{\mapsto}{\stackrel{\longrightarrow}{\hookrightarrow}}$

运 窇

$\frac{\pi}{8}$
$\substack{0 \\ 0}$
an

응

。

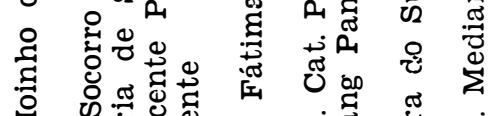

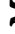

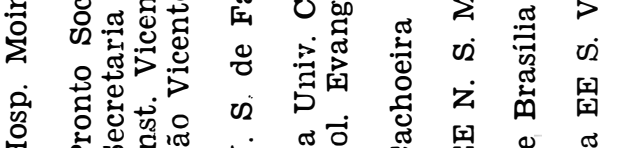

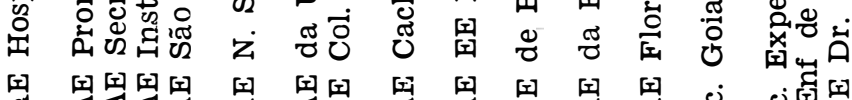

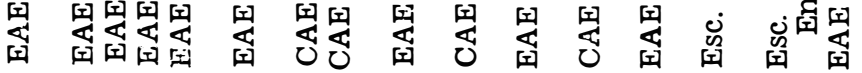

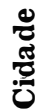

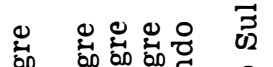

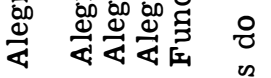

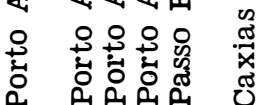

表

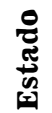

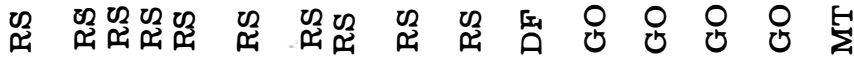

㕕 ミ 